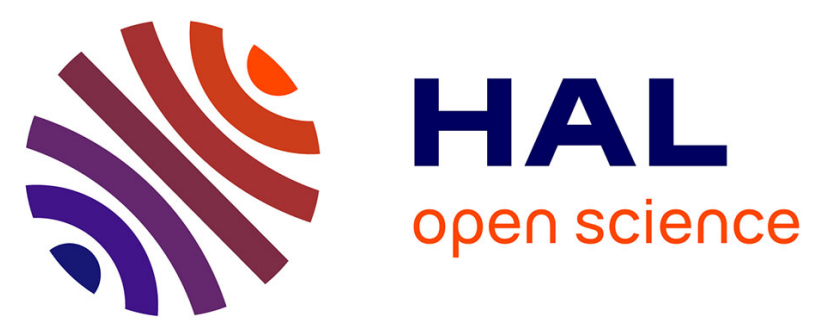

\title{
Insights into Water Adsorption in Potassium-Exchanged X-type Faujasite Zeolite: Molecular Simulation and Experiment
}

\author{
Tarik Ammouli, Jean-Louis Paillaud, Habiba Nouali, Régis Stephan, \\ Marie-Christine Hanf, Philippe Sonnet, Irena Deroche
}

\section{To cite this version:}

Tarik Ammouli, Jean-Louis Paillaud, Habiba Nouali, Régis Stephan, Marie-Christine Hanf, et al.. Insights into Water Adsorption in Potassium-Exchanged X-type Faujasite Zeolite: Molecular Simulation and Experiment. Journal of Physical Chemistry C, 2021, 125 (35), pp.19405-19416. 10.1021/acs.jpcc.1c03593 . hal-03410512

\section{HAL Id: hal-03410512 https://hal.science/hal-03410512}

Submitted on 2 Nov 2021

HAL is a multi-disciplinary open access archive for the deposit and dissemination of scientific research documents, whether they are published or not. The documents may come from teaching and research institutions in France or abroad, or from public or private research centers.
L'archive ouverte pluridisciplinaire HAL, est destinée au dépôt et à la diffusion de documents scientifiques de niveau recherche, publiés ou non, émanant des établissements d'enseignement et de recherche français ou étrangers, des laboratoires publics ou privés. 


\section{Insights into Water Adsorption in Potassium-Exchanged X-type Faujasite Zeolite: Molecular Simulation and Experiment}

Tarik Ammouli, Jean-Louis Paillaud, Habiba Nouali, Régis Stephan, Marie-Christine Hanf, Philippe Sonnet, and Irena Deroche*

Institut de Science des Matériaux de Mulhouse (IS2M), UMR 7361 CNRS, Université de Haute-Alsace, 68100 Mulhouse, France Université de Strasbourg, Strasbourg, France

* Corresponding author.

To cite this article: Insights into Water Adsorption in Potassium-Exchanged X-type Faujasite Zeolite: Molecular Simulation and Experiment, J. Phys. Chem. C 2021, 125(35), 19405-19416. DOI : 10.1021/acs.jpcc.1c03593, HAL : hal-03410512.

Received April 21, 2021; Received in revised form August 17, 2021; Available online August 27, 2021

Keywords: potassium exchanged X-type faujasite, Monte Carlo molecular simulation, DFT, adsorption isotherms, water molecules location,

cationic distribution

ABSTRACT: In the present study, we have combined several atomic-scale computational techniques [static lattice optimization, density functional theory (DFT), canonical Monte Carlo (MC), and Gibbs ensemble MC (GEMC)] with experiment in order to describe the adsorption of water in potassium-exchanged Xtype faujasite. Indeed, by applying DFT calculations, we have evidenced a strongly heterogeneous adsorbent surface and classified the preferential adsorption sites at zero loading for water molecules. The sodalite cage was identified as the preferential location. Moreover, by applying the GEMC technique, we have successfully simulated the water adsorption isotherm in the $\mathrm{K}-\mathrm{X}$ zeolite. Finally, through the canonical MC simulation, we have described the microscopic mechanisms of water adsorption within the $\mathrm{K}-\mathrm{X}$ zeolite at various uptakes, ranging from low loading $\left(8 \mathrm{H}_{2} \mathrm{O} /\right.$ unit cell) to saturation $\left(240 \mathrm{H}_{2} \mathrm{O} /\right.$ unit cell $)$. We have evidenced that at low loading, the sodalite cages host the major part of the adsorbed molecules, while at increasing hydration ratio, the water molecules locate more in supercages. At saturation, each sodalite cage accommodates more than three water molecules on average, whereas nearly $90 \%$ of water molecules are located within supercages. Finally, at any hydration ratio, the water molecules in supercages coordinate preferentially with potassium cations at crystallographic site III (or III') rather than at site II. Cations in site II start interacting with water molecules only at uptakes superior to $80 \mathrm{H}_{2} \mathrm{O}$ molecules/unit cell, once all cations in site III (or III') are occupied by at least one water molecule.

\section{INTRODUCTION}

Zeolites, aluminosilicate crystalline materials with an ordered microporous structure, formed by linking silicon and aluminum tetrahedra, aroused a huge scientific interest related to a wide number of their potential applications, in particular, in environmental remediation. ${ }^{1-5}$ Among the approximately 250 identified zeolite structures, ${ }^{6}$ the faujasite (FAU) has attracted a special attention due to its interesting structural, textural, and chemical properties. Indeed, FAU-type zeolites possess a large microporous volume, accessible even to pollutants with a significant molecular size. ${ }^{7}$ Moreover, its chemical composition can be fine-tuned through (1) a broad interval of Si/Al ratios, with which it can be synthesized or postsynthetically modified $(1<\mathrm{Si} / \mathrm{Al}<\infty),{ }^{8}$ and $(2)$ cationic exchange involving a large number of extra-framework cations. ${ }^{9}$ The FAU framework is built on the basis of fused double six-rings (D6Rs), (also called hexagonal prisms) and sodalite cages (also called $\beta$-cages). Each sodalite cage is interconnected via a hexagonal prism to four other sodalite cages in a tetrahedral configuration. The resulting honeycomb arrangement of sodalite cages interconnected through D6Rs stacked in a cubic way forms large cages commonly called the "supercage" (also called $\alpha$-cage) with a diameter of approximately $13 \AA$ (Figure 1a). The charge-compensating extra-framework cations in the FAU zeolite are usually distributed among five distinct crystallographic sites, designed as I, I', II, III, and III' (Figure 1b). The cationic sites within the framework are respectively localized as follows in the space group $F d \overline{3}$ : site I (Wyck. 16c) at the center of the hexagonal prism and site I' (Wyck. 32e) within the sodalite cage, close to a six-membered ring (6-MR) belonging to a hexagonal prism. The other cationic sites are located in the supercage: site II (Wyck. 32e) close to a 6-MR separating the supercage from a sodalite cage, site III (Wyck. 48f) close to a four-membered ring (4-MR), and finally site III' (Wyck. 96g) shifted from site III into the plane of the twelvemembered ring (12-MR) separating two supercages. It has been shown that the distribution of charge-compensating cations over the crystallographic sites is modified by the presence of water within the zeolite pores and evolves with the hydration ratio. ${ }^{10,11}$ 
(a)

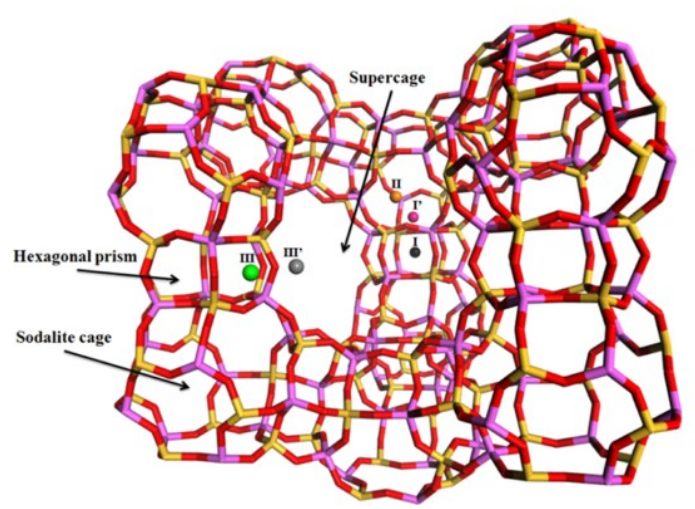

(b)

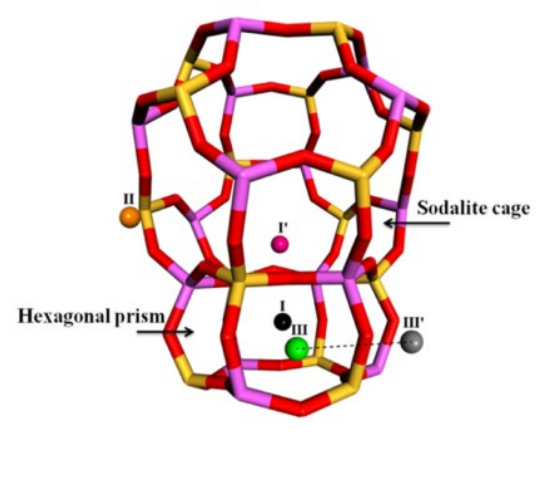

Figure 1. Atomic representation of the FAU framework showing (a) supercage and (b) detailed charge-compensating cation crystallographic sites, noted I, I', II, III, and III'. Red, yellow, lilac, black, pink, orange, green, and gray correspond respectively to species $\mathrm{O}, \mathrm{Si}, \mathrm{AI}, \mathrm{K}(\mathrm{I}), \mathrm{K}\left(\mathrm{I}^{\prime}\right), \mathrm{K}(\mathrm{II}), \mathrm{K}(\mathrm{III})$, and $\mathrm{K}(\mathrm{III})$. For clarity, each potassium nonequivalent position is represented once.

Although the scientific literature counts quite a large number of experimental, simulation, and combined studies of the structure, cation distribution, and adsorption properties of FAU zeolites containing $\mathrm{Na}^{+}$, the other alkali cation-exchanged faujasites have been more scarcely treated. However, potassium-exchanged zeolites have shown drastically improved performances in various catalytic processes ${ }^{12-14}$ or environmental applications. ${ }^{15} \mathrm{~A}$ couple of experimental and molecular simulation studies aimed to determine cation locations, especially in the dehydrated, partially or totally potassiumexchanged low silica X-type faujasite (LSX), characterized by the ratio Si/Al = 1. Paillaud et al. localized, through the Rietveld analysis, the cations within the dehydrated K-LSX. In particular, they observed a lowering of the symmetry from a cubic to orthorhombic structure (space group Fddd), thus tripling the number of crystallographic T sites (also proved from ${ }^{29} \mathrm{Si}$ MAS NMR), and a simultaneous occupation of the adjacent crystallographic sites I' and la, (the latter corresponding to a slightly off-centered site I, initially located in the middle of the D6R). ${ }^{16}$ This experimental evidence was further confirmed using classical interaction potential-based simulations, ${ }^{17}$ and the origin of the phenomenon was explained through localized basis set DFT calculations using cluster models. ${ }^{18}$ The previously experimentally observed $\mathrm{K}^{+}$distribution in the fully dehydrated single-crystal $\mathrm{K}-\mathrm{X}$ zeolite with the Si/Al $=1.09$ ratio is relatively similar. ${ }^{19}$ Lee et al. in their study on hydrated $\mathrm{K}-\mathrm{X}$ evidenced a full occupation of sites I and II by $\mathrm{K}^{+}$cations, whereas the electron density in the sodalite cage was attributed to water molecules, supposing the distance separating the cationic sites $I$ and $I^{\prime}$ is too short to be simultaneously occupied. ${ }^{20}$

Furthermore, only a few studies brought some experimental evidence on the water location in partially potassiumexchanged FAU zeolites. Kirschhock et al. attempted to localize residual water within partially $\mathrm{K}^{+}$-exchanged $\mathrm{X}$ zeolites of chemical formula $\mathrm{Na}_{22} \mathrm{~K}_{66} \mathrm{Al}_{88} \mathrm{Si}_{104} \mathrm{O}_{384}$ through the Rietveld refinement method. All the seven remaining $\mathrm{H}_{2} \mathrm{O}$ molecules per unit cell after dehydration under a $\mathrm{He}$ atmosphere were localized in the supercage, in exclusive interaction with $\mathrm{Na}^{+}$cations, all located in site II* (site II slightly displaced in the direction of the supercage center). ${ }^{21}$ Similar results on identical samples were observed through temperature-programmed desorption (TPD) combined with X-ray diffraction (XRD) study. ${ }^{22}$

As far as we know, until now, there is no extended scientific evidence of the localization of water molecules within the fully potassiumexchanged X-type faujasite, moreover when varying the hydration rate. Therefore, in the present study, we combine interatomic potentialbased $\mathrm{MC}$ and ab initio simulations with experimental techniques (X-ray fluorescence and adsorption manometry) in order to fill the gap in the existing water/potassium-exchanged X-type zeolite interaction and localization data.

\section{MATERIALS AND METHODS}

2.1 Computaional Methodology. 2.1.1. Microscopic Model for the Dehydrated Potassium-Exchanged X-Type Faujasite Structure. We applied a two-stage computational process in order to prepare a realistic microscopic model for the fully dehydrated K-X zeolite. First, starting with the experimental $\mathrm{Na}-\mathrm{X}$ structure reported by Zhu et al., ${ }^{23}$ that is, a cubic unit cell of lattice parameter $25.08 \AA$ of chemical composition given by $\mathrm{Si}_{100} \mathrm{Al}_{92} \mathrm{Na}_{92} \mathrm{O}_{384}$, with $\mathrm{Al}$ atoms distributed along the framework in accordance with the Löwenstein rule, we replaced the $\mathrm{Na}^{+}$cations with $\mathrm{K}^{+}$cations. The system was then geometry-optimized using the formally charged force field parameter set described by Jackson and Catlow ${ }^{24}$ and by applying the GULP code. ${ }^{25}$ The optimized cationic distribution was validated by comparison with the accessible data. ${ }^{17-19}$ The geometry of the K-X classical potential-based energy-minimized structure was further optimized with DFT, a first-principle method.

For the subsequent MC simulation, the faujasite system is assumed to be semi-ionic with atoms carrying partial charges, as detailed in Table 1. 
Table 1. Lennard-Jones ( $\varepsilon$ and $\sigma$ ) Parameters and Partial Atomic Charges (q) Carried by the Adsorbate and Adsorbent Atoms

\begin{tabular}{|c|c|c|c|}
\hline \multicolumn{3}{|c|}{ parameters for the non-bonded interactions } & \multirow[b]{2}{*}{$q(e)$} \\
\hline atom & $\varepsilon / \mathrm{k}_{\mathrm{B}}(\mathrm{K})$ & $\sigma(\AA)$ & \\
\hline $\mathrm{H}\left(\mathrm{H}_{2} \mathrm{O}\right)$ & 0 & 0 & 0.241 \\
\hline $\mathrm{O}\left(\mathrm{H}_{2} \mathrm{O}\right)$ & 80.52 & 3.12 & 0 \\
\hline $\mathrm{L}\left(\mathrm{H}_{2} \mathrm{O}\right)$ (lone pair interaction site) & 0 & 0 & -0.241 \\
\hline $\mathrm{O}$ (zeolite) & 78.20 & 3.17 & -1.20 \\
\hline Si (zeolite) & $0.93 \times 10^{-3}$ & 3.30 & 2.40 \\
\hline Al (zeolite) & $0.93 \times 10^{-3}$ & 3.30 & 1.40 \\
\hline $\mathrm{K}^{+}$ & 50.30 & 3.33 & 1.00 \\
\hline
\end{tabular}

2.1.2. Microscopic Model for the Water Molecules. Water molecules were described using the TIP5P five-site model initially developed to reproduce its liquid density. ${ }^{26}$ Within the frame of this model, the water internal structure is considered rigid with the $\mathrm{OH}$ bond length and $\mathrm{HOH}$ angle fixed to the experimental gas-phase values, respectively of $0.9572 \AA$ and $104.52^{\circ}$. The model distinguishes between electrostatic chargebearing sites and repulsion-dispersion sites. Thus, the partial charges are distributed as follows: a charge of $0.241 \mathrm{e}$ (where $\mathrm{e}=1.6 \times 10^{-19} \mathrm{C}$ ) is placed on each hydrogen site, and opposite value charges $(-0.241 \mathrm{e})$ are placed on the lone-pair interaction sites (designed as $\mathrm{L}$ ). Then, only the repulsion-dispersion interaction is considered between the oxygen atoms.

2.1.3. FAU Zeolite/Adsorbate Molecule Interaction Potential. In our model, the zeolite and the water molecules interact exclusively through a pairwise additive potential. These nonbonding intermolecular interactions are modeled through the addition of a Coulomb term and van der Waals energy, described through the conventional Lennard-Jones (12-6) function (eq. (1). The latter includes short-range repulsion associated with an important energy increase induced by shortening the distance separating the two atoms and the attractive dispersion energy. ${ }^{27}$

In (eq (1), qi and qj are the electrostatic site partial charges, rij is the distance separating the two interacting sites, and $\varepsilon i j$ and oij are the corresponding LJ interatomic potential parameters. Both, the partial atomic charges and the LJ interatomic parameters for the potassium-exchanged X-type faujasite, were taken from the Clay force field. ${ }^{28}$ The whole set of all applied parameters is reported in Table 1. The same force field parameters have been previously successfully applied in order to describe the adsorption properties of dichlorobenzene molecules in NaX zeolites. 4 Finally, the cross-term LJ parameters were calculated through the Lorentz-Berthelot mixing rule.

$$
U_{i j}^{i n t e r}=4 \varepsilon_{i j}\left[\left(\frac{\sigma_{i j}}{r_{i j}}\right)^{12}-\left(\frac{\sigma_{i j}}{r_{i j}}\right)^{6}\right]+\frac{q_{i j} q_{j}}{4 \pi \varepsilon_{0} r_{i j}}
$$

2.1.4. MC Simulation. The Gibbs ensemble MC (GEMC) simulation was applied to simulate the water adsorption isotherm, and to determine both potassium cation distribution along the cationic crystallographic sites and water molecule localization in the potassiumexchanged X-type zeolite, with varying water contents.

The absolute adsorption isotherm of water was computed at $298 \mathrm{~K}$ in the potassium-exchanged X-type faujasite, applying the configurational-bias MC simulation within the isobaric-isothermal (NpT) version of the Gibbs ensemble, ${ }^{27}$ implemented within the 8.0.0 version of the Towhee code. ${ }^{29}$ We applied the osmotic version of the Gibbs ensemble, where only the adsorbate molecules are allowed to transfer between the gas-phase reservoir and zeolite. The major advantages of such a simulation set are a close imitation of the experimental setup and no need of chemical potential calculation. In this type of simulation, the pressure of the system is imposed through an explicit reservoir containing the adsorbate species. In our case, the system used for all simulations contained a total of 2000 water molecules, distributed between the gas phase and the adsorbed phase. ${ }^{27}$ The GEMC simulations consisted of evaluating the average number of adsorbate molecules in equilibrium with the bulk phase reservoir at a given pressure and temperature.

The distributions of potassium cations along the crystallographic sites in the $\mathrm{K}-\mathrm{X}$ zeolite and of water molecules, with varying 
hydration ratios $\left(\mathrm{H}_{2} \mathrm{O}\right.$ wt \% $\in[0 ; 29] ; \mathrm{H}_{2} \mathrm{O}$ molecules number per $\mathrm{K}-\mathrm{X}$ unit cell $\left.\in[0 ; 240]\right)$, were investigated employing the $\mathrm{MC}$ simulation in the canonical ensemble.

In order to achieve a higher efficiency of the MC scheme, we applied the energy-bias algorithm. Thus, through inserting molecules in an energetically favorable phase space, we reached a better acceptance probability. ${ }^{30}$ Furthermore, it has been shown that, in order to achieve a correct configurational space sampling, one needs to allow the extra-framework cations to relax. ${ }^{31}$ Thus, while all framework atoms $(\mathrm{Si}, \mathrm{Al}$, and $\mathrm{O})$ were kept fixed all along the $\mathrm{MC}$ simulations, the potassium cations were allowed to undergo displacements. $\mathrm{A}$ typical MC run consisted of $1.0 \times 10^{7}$ steps for the equilibration phase and $2.0 \times 10^{7}$ steps for the production phase. In order to sample the configurational part of the phase space, we employed the following MC moves: water molecule center of mass translation, rotation, water molecule intrabox swap move, potassium cation translation, box volume change (this move was applied exclusively to the reservoir phase and not to the zeolite framework), and water molecule transfer move between the explicitly simulated reservoir and the zeolite containing box (exclusively in the GEMC ensemble). The maximum displacements for translation, rotation, and volume moves were adjusted throughout the equilibration period to yield acceptance rates near $50 \%$. The periodic conditions were applied in all directions of the space. The Ewald summation technique was used in the calculation of the long-range electrostatic interactions. A short-range repulsion-dispersion interaction cut-off of $12.5 \AA$ was applied. Finally, the isosteric heat of adsorption was calculated through the fluctuation over the number of adsorbed molecules and from the internal energy. ${ }^{32}$

2.1.5. DFT Calculation Parameters. The starting configurations for the geometry optimizations on the DFT level were obtained by the canonical MC simulation-based approach, described above. An equilibration period (consisting of $1.0 \times 10^{7} \mathrm{MC}$ steps), followed by a production period, allowed us to select the low-energy configurations. Subsequent optimizations were achieved using the periodic DFT calculations, performed on both the activated (totally dehydrated) $\mathrm{K}-\mathrm{X}$ zeolite and $\mathrm{K}-\mathrm{X}$ containing one water molecule per unit cell, adsorbed at different adsorption sites. The aims of this approach were (1) to determine the optimized geometry of the activated structure and (2) to find the preferential location of the water molecules within the zeolite structure. During each geometry optimization run, only atomic positions were relaxed, keeping the unit cell rigid, while the cell volume was adjusted through an $r$ scale factor between 0.99 and 1.02 and with a step of 0.01 . This approach allowed us to determine the energy minimum cell volume through the Murnaghan fit. ${ }^{33}$ The geometry optimizations were realized using the PBE GGA functional ${ }^{34}$ with D2 dispersion correction ${ }^{35}$ and pseudopotentials described by the projector-augmented wave method (PAW) ${ }^{36}$ as implemented in the Vienna ab-initio simulation package (VASP). ${ }^{37}$ The plane wave cutoff was set to $500 \mathrm{eV}$ to ensure convergence. The total number of atoms was 668 for the dehydrated potassium-exchanged X-type faujasite. Due to the large cell size, only the $\Gamma$ point was used to sample the Brillouin zone. The convergence criterion based on the residual force calculation, exerted on atoms calculated through the Feynman method, was set up to $0.02 \mathrm{eV} / \AA$. Moreover, the charge difference isosurfaces were visualized using the visual molecular dynamics (VMD) software developed by the Theoretical and Computational Biophysics Group in the Beckman Institute for Advanced Science and Technology at the University of Illinois at UrbanaChampaign. 38,39

The geometry of the water molecule was also separately optimized (in a box with $\mathrm{K}-\mathrm{X}$ unit cell dimensions), in order to set its reference state. The water adsorption energy in the $\mathrm{K}-\mathrm{X}$ zeolite was than estimated through the formula

$$
\mathrm{E}_{\mathrm{ad}}=\mathrm{E}_{\left(\mathrm{H}_{2} \mathrm{O}-\mathrm{X}\right)}-\mathrm{E}_{(\mathrm{K}-\mathrm{X})}-\mathrm{E}_{\left(\mathrm{H}_{2} \mathrm{O}\right)}
$$

where $\mathrm{E}_{\left(\mathrm{H}_{2} \mathrm{O} / \mathrm{K}-\mathrm{X}\right)}$ is the total energy of the whole system, $\mathrm{E}_{(\mathrm{K}-\mathrm{X})}$ is the total energy of the relaxed activated faujasite, and $\mathrm{E}_{(\mathrm{H} 2 \mathrm{O})}$ is the energy of a water molecule.

2.2. Experimental Section. 2.2.1. Cationic Exchange. The potassium-exchanged $X$-type faujasite samples were prepared by a cationic exchange from the commercial $\mathrm{Na}-\mathrm{X}$ zeolite at a Si/Al ratio of 1.23. Ion exchange was achieved using an aqueous solution of $\mathrm{K}\left(\mathrm{NO}_{3}\right)$ at a molar concentration of $1 \mathrm{~mol} \mathrm{~L}^{-1}$ at room temperature under stirring for $8 \mathrm{~h}$. In order to improve the cationic exchange rate, the procedure was repeated three times. The final degree of ion exchange was determined using the X-ray fluorescence technique with a PANalytical Zetium XRF spectrometer.

2.2.2. Manometric Measurements of Water Adsorption in the $K-X$ Zeolite. The water adsorption isotherm of the potassiumexchanged X-type faujasite sample was obtained at $298 \mathrm{~K}$ using a Micromeritics ASAP 2020 instrument. Prior to the water adsorption measurement, water was flash frozen under liquid nitrogen and then evacuated under dynamic vacuum several times in order to remove any possibly present gas molecule in the water reservoir. In order to remove the physisorbed water and thereby activate the samples (50-100 mg), they were beforehand outgassed through heating at a temperature of $300{ }^{\circ} \mathrm{C}$ under vacuum for $24 \mathrm{~h}$.

\section{RESULTS AND DISCUSSION}

3.1. Potassium Cation Distribution and Unit Cell. Volume of the Fully Dehydrated X-type Zeolite. In order to computationally determine the potassium cation distribution of the activated zeolite, we first carried out the classical potential-based geometry optimization, as described in Section 2.1.1, followed by DFT-based energy minimization. The resulting potassium cation distribution is detailed in Table 2 and illustrated in Figure 2b. 
Table 2. Geometry-Optimized Potassium Cations Distribution in the Activated Fully Potassium Exchanged X-type Zeolite at a Si/AI Ratio of 1.1.

\begin{tabular}{lcc}
\hline \multicolumn{1}{c}{ Cationic site (Environment) } & Number of $\mathrm{K}^{+}$ & Occupation rate (\%) \\
I (6-coordinated) & 15 & 94 \\
I' (3- coordinated) & 17 & 53 \\
II (3- coordinated) & 32 & 100 \\
III \& III' (2- coordinated) & 28 & 19 \\
\hline
\end{tabular}

Through the Murnaghan $\mathrm{fit}^{33}$ of the total optimized cell energy versus cell volume curve, plotted in Figure $2 \mathrm{a}$, we know that the determined optimized cell parameter is $25.33 \AA$, which corresponds to a cell volume increase of $\sim 3 \%$ compared to that of the $\mathrm{Na}-\mathrm{X}$ zeolite. Such a cell volume increase when exchanging the $\mathrm{Na}^{+}$cations with $\mathrm{K}^{+}$is in perfect agreement with both the experimental and molecular simulation evidence for similar materials. ${ }^{17,18,20}$ Furthermore, the $\mathrm{K}^{+}$distribution in our model shows a simultaneous occupation of crystallographic site I (center of the hexagonal prism) and neighboring site I' (sodalite cage), as previously described. The abovementioned co-occupation of neighboring sites I and I' is almost maximum; that is, each of the $16 \mathrm{D} 6 \mathrm{Rs}$ per unit cell contains one $\mathrm{K}^{+}$at site la and one neighbor $\mathrm{K}^{+}$at site I'; this high degree of cation crowding was first experimentally proven for the K-LSX zeolite. ${ }^{16}$ The distance measured between the $\mathrm{K}^{+}$cations in adjacent sites $\mathrm{I}$ and $\mathrm{I}^{\prime}$ is of $3.44 \AA$, which is in relatively good agreement with the results obtained by Gibbs et al. ${ }^{17}$ (3.512 $\AA$ in K-LSX), Guesmi et al. ${ }^{18}$ (3.59 $\AA$ in K-LSX), and Zhu et al. (3.79 $\AA$ in K-X). ${ }^{19}$

3.2. Preferential Water Adsorption Sites at Zero Coverage. Furthermore, we studied the preferential water molecule localization at zero loading, through a combination of canonical MC simulations and DFT calculations. By applying NVT-MC simulations, we prepared the starting structures containing one water molecule interacting with one $\mathrm{K}^{+}$cation at different crystallographic sites (I', II, and III) for subsequent DFT calculations. First, DFT results allowed us to classify the preferential locations of the water molecule within the $\mathrm{K}-\mathrm{X}$ zeolite pores. Furthermore, they allowed us to reveal both qualitative and quantitative descriptions of the interactions taking place between the $\mathrm{H}_{2} \mathrm{O}$ molecules and the adsorbent surface. The adsorption energies for one water molecule located at various crystallographic sites extracted from the DFT optimizations are summarized in Table 3. The huge adsorption energy difference between the three adsorption sites attests an energetic surface heterogeneity. According to the adsorption energy values (Table 3 ), the affinity of water molecules to $\mathrm{K}^{+}$cations located at various cationic sites decreases in the following order: I' > III' > II. The optimized geometries of the $\mathrm{K}-\mathrm{X}$ unit cell containing one water molecule as well as the adsorption-induced charge difference isosurfaces are represented in Figure 3 . The first water molecule preferential adsorption location is within the sodalite cage, containing three $\mathrm{K}^{+}$cations, all located in site $\mathrm{I}^{\prime}$, as illustrated in Figure 3a,b.

(a)

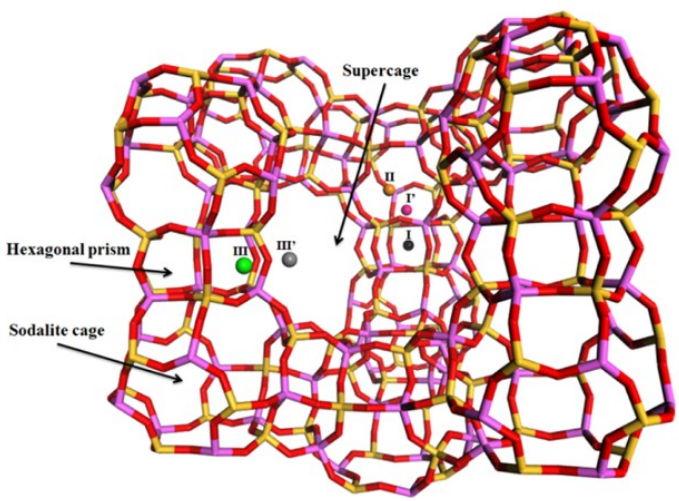

(b)

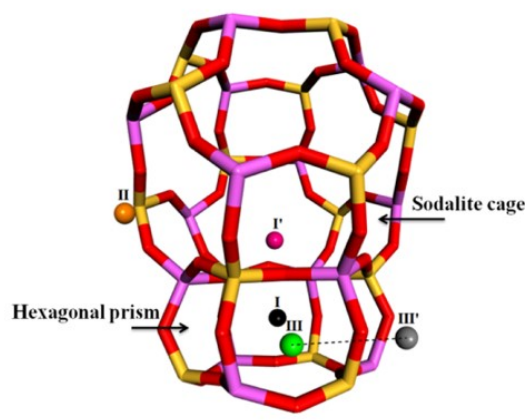

Figure 2. (a) Murnaghan fit of the total energy vs cell volume curve with the energy minimum determining the optimized unit cell volume and (b) illustration of the geometry-optimized $\mathrm{K}^{+}$cation distribution within the $\mathrm{K}-\mathrm{X}$ faujasite. Red, yellow, lilac, black, pink, orange, green, and gray correspond respectively to species $\mathrm{O}, \mathrm{Si}, \mathrm{Al}, \mathrm{K}(\mathrm{I}), \mathrm{K}\left(\mathrm{I}^{\prime}\right), \mathrm{K}(\mathrm{II}), \mathrm{K}(\mathrm{III})$, and $\mathrm{K}\left(\mathrm{III} \mathrm{I}^{\prime}\right)$.

A detailed inspection of the adsorption-induced charge difference isosurfaces allows us to determine the following notable interactions between the water molecule and the zeolite surface:

(1) two hydrogen bonds formed between the framework oxygen atoms and both water hydrogen atoms [respective $\mathrm{O}_{z}-\mathrm{H}\left(\mathrm{H}_{2} \mathrm{O}\right)$ distances of 2.05 and $2.29 \AA]$.

(2) three electrostatic interactions, namely between water oxygen and each of the $\mathrm{K}^{+}\left(\mathrm{I}^{\prime}\right)$ cations $\left[\right.$ with $\mathrm{O}\left(\mathrm{H}_{2} \mathrm{O}\right)-\mathrm{K}^{+}\left(\mathrm{I}^{\prime}\right)$ distances between 2.97 and $3.32 \AA]$. 
Table 3. Adsorption Energy for Water Molecules Interacting with Potassium Cations at Various Crystallographic Sites

\begin{tabular}{cc}
\hline $\mathrm{H}_{2} \mathrm{O}$ interacting $\mathrm{K}^{+}$crystallographic site & Adsorption energy $\left(\mathrm{kJ} . \mathrm{mol}^{-1}\right)$ \\
I' & -144.9 \\
II & -81.1 \\
III' & -111.8 \\
\hline
\end{tabular}

In its second preferential location, the water molecule is coordinated to a $\mathrm{K}^{+}$cation in site III', placed within the supercage in the plane of the 12-MR. As shown in Figure $3 \mathrm{e} f$, the water molecule interacts simultaneously through (1) two hydrogen bonds $\left[\mathrm{Oz}-\mathrm{H}\left(\mathrm{H}_{2} \mathrm{O}\right)\right.$ distances of $1.75 \AA$ and $\left.2.10 \AA\right]$ and (2) one electrostatic interaction between $\mathrm{K}+(\mathrm{III})$ and $\mathrm{O}\left(\mathrm{H}_{2} \mathrm{O}\right)($ distance of $2.79 \AA$ ). Finally, in its last adsorption site, the water molecule interacts with $\mathrm{K}^{+}$cations in crystallographic site II, through (1) a single hydrogen bond (length of $1.85 \AA$ ) and (2) a single electrostatic interaction $\left[\mathrm{K}^{+}-\mathrm{O}\left(\mathrm{H}_{2} \mathrm{O}\right)\right.$ distance of $\left.2.88 \AA\right]$, as illustrated in Figure 3c,d.

The most preferential adsorption site for water molecules is within the sodalite cage, which is the smaller cage of the faujasite structure, in agreement with several accessible literature data. Indeed, the adsorption, as a surface phenomenon, favors the occupation of smaller cages by adsorbent species, maximizing the adsorbate-adsorbent interactions. Such evidence was previously brought in analogous zeolites such as EMT possessing two types of cages with various sizes ${ }^{5}$ or LTA with smaller $\beta$-cages and bigger $\alpha$-cages. ${ }^{31}$ Furthermore, the sodalite cage as the most energetically favorable adsorption site has been suggested from the experimental ${ }^{40-42}$ as well as simulation point of view ${ }^{43}$ for the sodium $\mathrm{Y}$-type faujasite $(\mathrm{Na}-\mathrm{Y})$.

Nevertheless, we shall also address the question of sodalite cage accessibility, exclusively reachable by passing through the 6-MR with a diameter in the 2.2-2.8 $\AA$ range ${ }^{44}$ including the kinetic diameter of water $(d=2.65 \AA)$. Furthermore, occupation of cationic site II might, in a way, block the access and form additional difficulties that the water molecule should overcome in order to access the sodalite cage. ${ }^{45}$ In the present work, we consider that the sodalite cage is accessible to water molecules for the following reasons:

(1) Three $\mathrm{Al}$ atoms are present within the $6-\mathrm{MR}$ due to an almost strict alternation between $\mathrm{Si}$ and $\mathrm{Al}$ atoms in the $\mathrm{K}-\mathrm{X}$ framework, imposed by the low Si/Al ratio (1.1), thus increasing the 6-MR diameter ( 2.8 $\AA$ ) compared to the siliceous ones $(\sim 2.2 \AA)$, which should ease the water molecule access into the sodalite cage.

(2) The atomic radius of potassium is higher than that of sodium, and therefore, the cation-6-MR oxygen mean distance is also lengthened. ${ }^{46}$ Consequently, the less embedded cation in site II might let the water molecule diffuse through the 6-MR.

(3) The water molecule accessibility of the sodalite cage, addressed by simulation, experimental, and combined tools, has been recently exhaustively reviewed by Purdue and Qiao, ${ }^{47}$ who concluded that its accessibility in the $13 \mathrm{X}$ zeolite is analogous to our $\mathrm{K}-\mathrm{X}(\mathrm{Si} / \mathrm{Al}=1.1)$.

Then, according to our results, the water molecule preferably attaches to $\mathrm{K}^{+}$in crystallographic site III' compared to that in site II. Consistent data have been previously published in the literature for $\mathrm{CO}$ in $\mathrm{Na}-\mathrm{X}^{48}$ and for $\mathrm{DCIB}$ in $\mathrm{Na}-\mathrm{X}{ }^{4}$ This preference would take its origin in a more open geometry of site III', allowing the ad sorbate to strengthen the interactions with the adsorbent surface. This hypothesis is supported by the charge difference isosurfaces evidenced in Figure $3 d$, f, showing a stronger water/zeolite interaction for water located close to the $\mathrm{K}^{+}$cation in site III' compared to the one in site II.

3.3. Water Adsorption in $\mathbf{K}-\mathbf{X}$ at Varying Coverages. 3.3.1. Adsorption Isotherms and Isosteric Heat of Adsorption. The experimental isotherm was measured on a $\mathrm{K}-\mathrm{X}$ sample prepared by the ionic exchange from the commercial $\mathrm{Na}-\mathrm{X}(13 \mathrm{X})$ zeolite. Table S1 displays the chemical composition of the $\mathrm{K}-\mathrm{X}$ sample determined from XRF, showing a high degree ( 95\%) of cationic exchange. The high quality of the powder XRD patterns of the initial Na-X and exchanged K-X zeolites (Figure S1) proves a good crystallinity for both the initial and the exchanged samples. The different relative intensities of the reflections relate to the different nature of the compensating cations, which have different scattering factors.

Figure $4 \mathrm{a}$ evidences a good agreement between the adsorption isotherms of $\mathrm{H}_{2} \mathrm{O}$ in the potassium-exchanged X-type faujasite, determined at $303 \mathrm{~K}$ by GEMC simulation and manometric experiment. According to the IUPAC classification, ${ }^{49}$ the isotherms are of type I as expected for a microporous and roughly rigid adsorbent (without any kind of "breathing effect") an d present a well-defined saturation plateau at an adsorption amount of $240 \mathrm{H}_{2} \mathrm{O}$ molecules per unit cell.

The adsorption amount at saturation is quite well comparable with the published data for similar systems $\left(233 \mathrm{H}_{2} \mathrm{O}\right.$ molecules per unit cell). ${ }^{50,51}$ Furthermore, the isosteric heat of adsorption (Figure $4 \mathrm{~b}$, estimated from the GEMC simulation 
through the fluctuation formula) decreases with increasing adsorption amount, indicating an energetically heterogeneous surface. Nevertheless, the initial isosteric heat of adsorption $(\sim 95 \mathrm{~kJ} / \mathrm{mol})$ overestimates the experimentally measured one by Dzhigit et al. ${ }^{50}(\sim 80 \mathrm{~kJ} / \mathrm{mol})$. However, their X-type faujasite had a higher Si/Al ratio $(\mathrm{Si} / \mathrm{Al}=1.33)$ and was only partly exchanged with potassium $(66 \%)$.

Figure 3. On the left: perspective view of DFT-based geometryoptimized structures of $\mathrm{K}-\mathrm{X}$ zeolites containing one $\mathrm{H}_{2} \mathrm{O}$ molecule, interacting with $\mathrm{K}^{+}$ cations in crystallographic site I' (a), II (c), and III' (e). Selected interatomic distances are given in Angström $(\AA)$. On the right: graphical representations of charge-difference isosurfaces (isosurface values of $\pm 0.0035 \mathrm{e}-/ \AA^{3}$ ) induced by the adsorption of water in the $\mathrm{K}-\mathrm{X}$, in the vicinity of $\mathrm{K}^{+}$respectively in crystallographic sites I' (b), II (d), and III' (f). Gray (white) isosurface corresponds to electronic density decrease (increase). Red, yellow, pink, purple, and white correspond respectively to the following elements $\mathrm{O}, \mathrm{Si}, \mathrm{Al}$, $\mathrm{K}$, and $\mathrm{H}$.

3.3.2. Water Molecule Locations at Various Loadings. Aiming to refine the location of water molecules when varying the hydration ratio, we achieved a set of canonical MC (NVT-MC) simulations of the $\mathrm{K}-\mathrm{X}$ zeolite containing various numbers of water molecules. In particular, we explored $\mathrm{K}-\mathrm{X}$ respectively with $8,20,40,80,120,160$, and 240 water molecules per unit cell, corresponding to approximate hydration rates of $1.0,2.5,5.0,10.0,14.3,19.0$, and 28.7 wt \%. Figure 5 shows the radial distribution functions (RDFs), related to the probability of having an atom situated at a particular distance from a point, for the water atoms relative to the center of the sodalite cage and of the supercage. The comparison of graphics relative to the sodalite cage and to the supercage brings to light the water molecule preferential adsorption within the sodalite cage at low hydration rates. Table 4 summarizes for each hydration ratio, respectively, the number of water molecules located in the sodalite cage and in the supercage, expressed as the mean water molecule number per $\beta$ cage and $\alpha$-cage, and the respective ratios from the total water uptake. One can claim, in accordance with all previous statements, that at a low hydration rate ( $1 \mathrm{wt} \%)$, a majority of water molecules
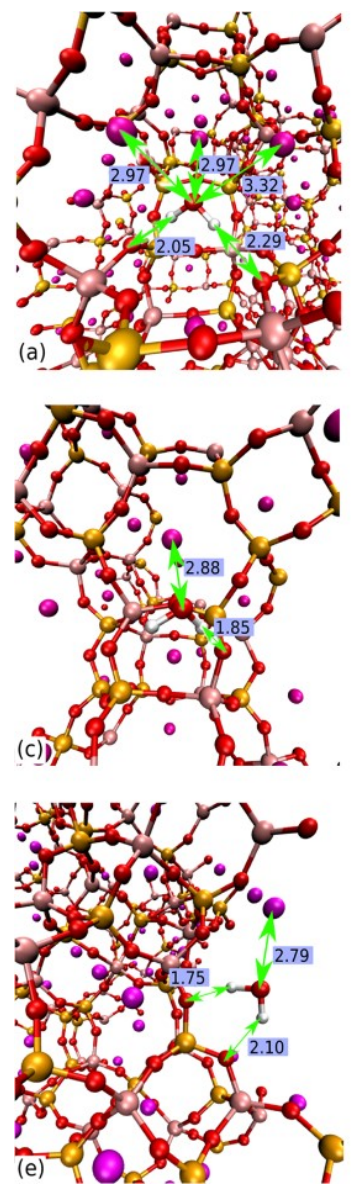
occupy sodalite cages. On increasing the uptake, the water molecules fill the supercages and their proportion localized in sodalite cages decreases. Near saturation, the sodalite cage hosts, on average, 3.5 water molecules, whereas $88 \%$ of water molecules is located within supercages with a mean occupation of 26.4 molecules per supercage. Furthermore, an estimation of the porous volume of a supercage, through the calculation of the Connolly surface, taking into account the excluded volume due to the presence of potassium cations ( $V p=662 \AA^{3} /$ supercage), allowed us to obtain the water density at a saturation of $1.19 \mathrm{~g} \mathrm{~cm}^{-3}$. This density is higher than that of bulk water which has been already described for hydrophilic adsorb ents. ${ }^{52}$

Moreover, for $g(r)$ relative to the pair sodalite cage center-water oxygen, one can observe a shift in the maximum toward higher distances with increasing uptake. This translates the evolution of the water molecule sitting within the sodalite cage, located closer to its center at initial loading (one molecule per sodalite cage) and moving toward the framework when each sodalite cage hosts several water molecules. An opposite phenomenon is observed within supercages, where increasing the loading induces a shift in the $g(r)$ maximum position toward shorter distances. Indeed, at low loading, the water molecules inside the supercages are separated by $\sim 5.5 \AA$ from their centers. This indicates their localization within the 12-MR separating two supercages. Such water molecule localization has been experimentally observed in the $\mathrm{Na}-\mathrm{Y}$ zeolite. ${ }^{40}$ This allows the water molecule to stabilize through (1) two hydrogen bonds with framework oxygen atoms and (2) an electrostatic interaction with a $\mathrm{K}^{+}$cation in crystallographic site III'. Then, at intermediate loadings, the maximum shifts to shorter distances, and at high loadings, close to saturation, a new peak on $g(r)$ appears indicating the supercage filling with water molecules located closer to the supercage center. 
(a)

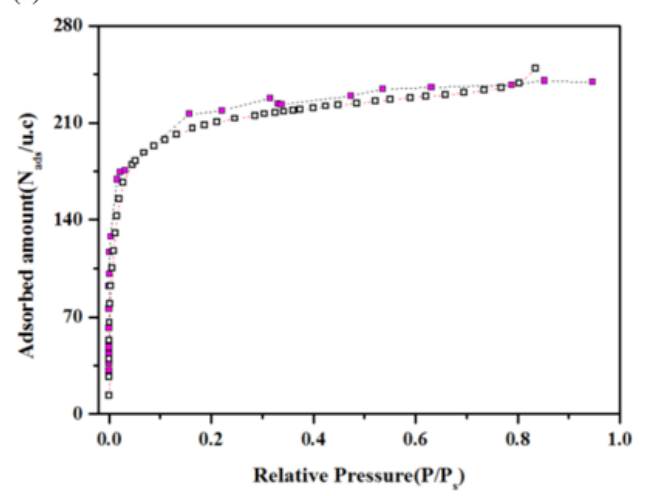

(b)

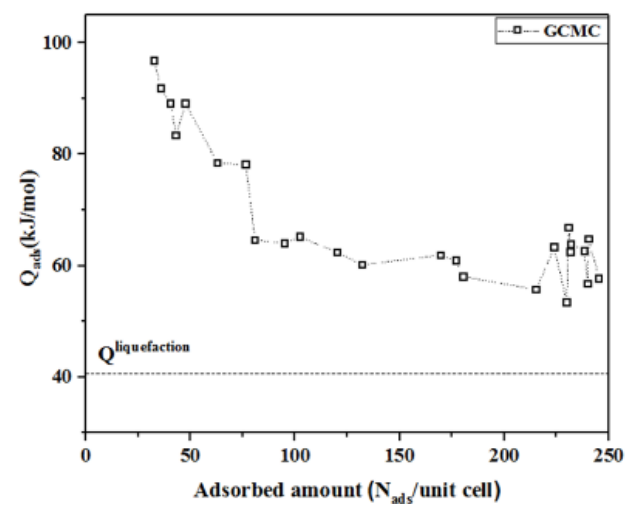

Figure 4. (a) Comparison of measured (empty symbols) and simulated (full symbols) adsorption isotherms of water in $\mathrm{K}-\mathrm{X}$ at $303 \mathrm{~K}$. (b) Evolution of the isosteric heat of adsorption as a function of the adsorption amount.

(a)

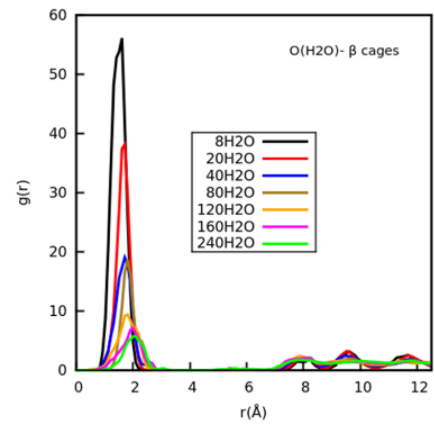

(c)

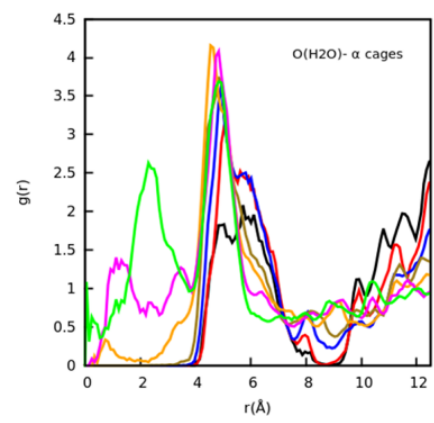

(b)

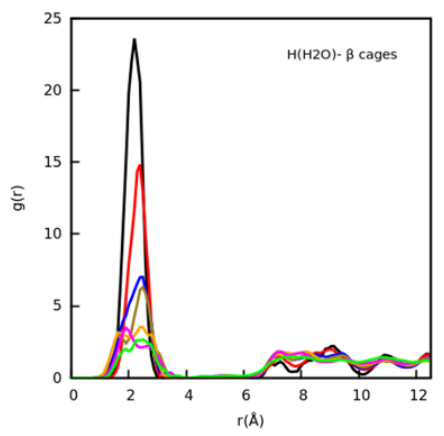

(d)

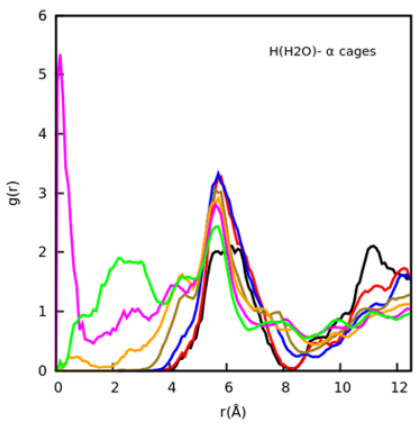

Figure 5. RDFs for (a) oxygen atom of the water molecule and sodalite cage center, (b) hydrogen atom of the water molecule and sodalite cage center, (c) oxygen atom of the water molecule and supercage center, and (d) hydrogen atom of the water molecule and supercage center. 
Table 4. Average Number of Water Molecules Located in Sodalite Cages and in Supercages at Each Hydration Ratio

\begin{tabular}{ccccc}
\hline $\mathrm{H}_{2} \mathrm{O} /$ unit cell & $\mathrm{H}_{2} \mathrm{O} / \beta$-cage & $\% \mathrm{H}_{2} \mathrm{O}$ in $\beta$-cages & $\mathrm{H}_{2} \mathrm{O} / \alpha$-cage & $\% \mathrm{H}_{2} \mathrm{O}$ in $\alpha$-cages \\
\hline 8 & 0.6 & 63 & 0.4 & 37 \\
\hline 20 & 0.9 & 35 & 1.6 & 65 \\
\hline 40 & 1.2 & 25 & 3.8 & 75 \\
\hline 80 & 2.3 & 23 & 7.8 & 83 \\
\hline 120 & 2.5 & 17 & 12.5 & 86 \\
\hline 160 & 2.8 & 14 & 17.3 & 88 \\
\hline 240 & 3.6 & 12 & 26.4 &
\end{tabular}

3.3.3. Specific Water-Potassium Cation Interaction upon Hydration. Figure 6 shows the $g(r)$ for the $\mathrm{K}^{+}$cation at various crystallographic sites and the oxygen atom of the water molecule, for all investigated hydration ratios. Consequently, one can depict the specific interactions between potassium cations at different crystallographic sites and water molecules, for various hydration rates. Moreover, the running coordination number $n(r)$ is also plotted in Figure 6. From the $n(r)$ at the distance of the first minimum, one can extract the number of water molecules in the first coordination sphere of the cation in each crystallographic site and its variation with the hydration ratio. These coordination numbers are reported in Table 5. In agreement with the above presented data, one can observe the major interaction at low loading $\left(8 \mathrm{H}_{2} \mathrm{O} /\right.$ unit cell) between the water molecule and the cation in site $\mathrm{I}^{\prime}$, within the $\beta$-cage, with a characteristic distance of $2.7 \AA$. At low hydration ratios, cations in site I' also have the highest coordination number (Table 5). Furthermore, at low loading, water molecules also locate in the supercage, more specifically in the plane of the 12-MR and exclusively in the vicinity of cations in sites III and III', with an identical interatomicdistance $(2.7 \AA)$. On the other hand, at initial loadings, no water molecule interacts with the cation in site II, as supported by a nearly zero coordination number (Table 5). Only when increasing the water uptake up to $80 \mathrm{H}_{2} \mathrm{O} / \mathrm{unit}$ cell, (corresponding to an occupation of each cation in site III' by at least one water molecule), cations in site II start to be coordinated by water molecules. Moreover, the coordination number of water molecules surrounding each cation increases with loading and is always higher for $\mathrm{K}^{+}$cations in site III' compared to those in site II. These outcomes are perfectly coherent with the observations of Shirono et al. from their molecular dynamics study on the hydrated zeolites $\mathrm{Na}-\mathrm{X}$ and $\mathrm{Na}-\mathrm{Y} .{ }^{53}$ Then, in order to describe the structure of water adsorbed within the $\mathrm{K}-\mathrm{X}$ zeolite, we have plotted the $g(r)$ for the interaction between two water oxygen atoms, shown in Figure 7. At high loading one observes the formation of a structure analogous to bulk water, ${ }^{42,52}$ with the $\mathrm{O}\left(\mathrm{H}_{2} \mathrm{O}\right)-\mathrm{O}\left(\mathrm{H}_{2} \mathrm{O}\right)$ and $\mathrm{O}\left(\mathrm{H}_{2} \mathrm{O}\right)-\mathrm{H}\left(\mathrm{H}_{2} \mathrm{O}\right)$ distances of $2.77 \AA$ and $1.81 \AA$, respectively, as previously observed for the NaY zeolite experimentally ${ }^{42}$ or for various purely siliceous zeolites from a simulation point of view. ${ }^{52}$

(a)

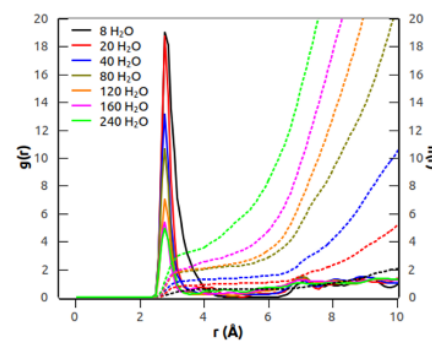

(c)

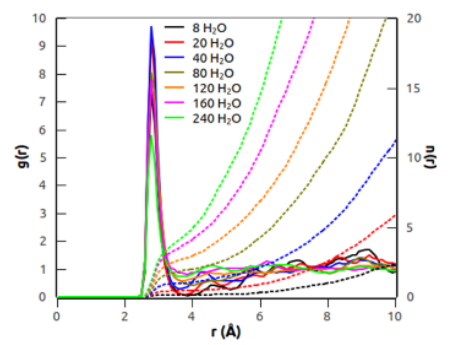

(b)

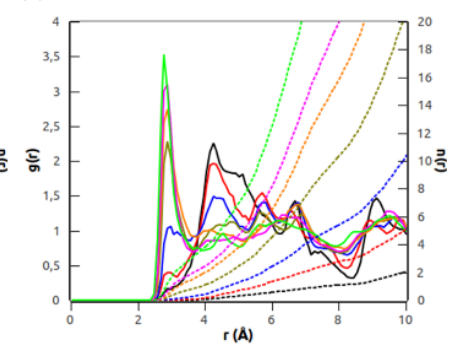

Finally, Figure 8 shows snapshots of 2000 superimposed configurations of $\mathrm{H}_{2} \mathrm{O}$ adsorbed in one unit cell of the $\mathrm{K}-\mathrm{X}$ zeolite, at respective loadings of (a) $20 \mathrm{H}_{2} \mathrm{O} /$ unit cell, (b) $40 \mathrm{H}_{2} \mathrm{O} /$ unit cell, (c) $80 \mathrm{H}_{2} \mathrm{O} /$ unit cell, (d) $120 \mathrm{H} 2 \mathrm{O} / \mathrm{unit}$ cell, (e) 160 $\mathrm{H}_{2} \mathrm{O}$ /unit cell, and (f) $240 \mathrm{H}_{2} \mathrm{O}$ /unit cell. This illustrates the typical location and arrangement of water molecules, which is in 
perfect agreement with DFT results. At the initial stage of coverage, the water molecules occupy preferentially the sodalite cages (interacting with $\mathrm{K}^{+}$cations in the crystallographic site $\mathrm{I}^{\prime}$ ) and to some extent also the supercages (exclusively located within the 12-MR and in interaction with cations in sites III'). On increasing the loading, the supercages are more filled with water molecules, interacting with both cations in sites III and III' and subsequently with cations in site II. Finally, close to the saturation, water molecules occupy all the available space, even the center on the supercages.

Table 5. Coordination Number for $\mathrm{K}^{+}$Cations in Various Crystallographic Sites as a Function of Water Loading.

\begin{tabular}{cccc}
\hline $\mathrm{H}_{2} \mathrm{O} /$ unit cell & I' & II & III\&II' \\
\hline 8 & 0.47 & 0.01 & 0.14 \\
20 & 0.80 & 0.04 & 0.42 \\
40 & 1.15 & 0.19 & 0.93 \\
80 & 1.83 & 0.65 & 1.69 \\
120 & 1.91 & 1.19 & 2.43 \\
160 & 2.01 & 1.62 & 3.19 \\
240 & 3.14 & 2.55 & 3.65 \\
\hline
\end{tabular}

(a)

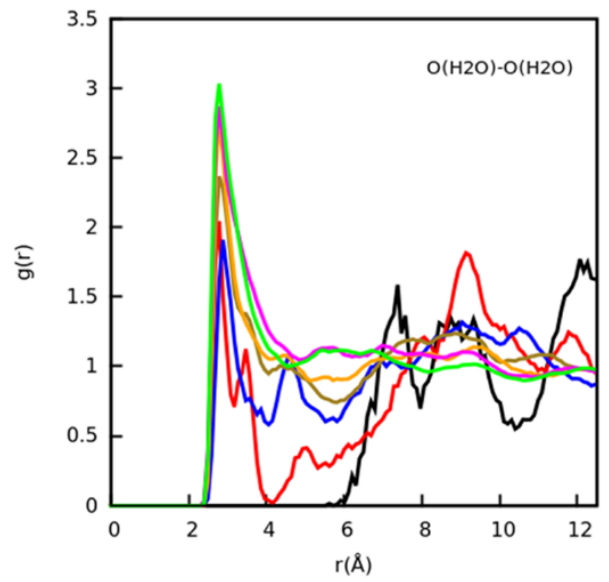

(b)

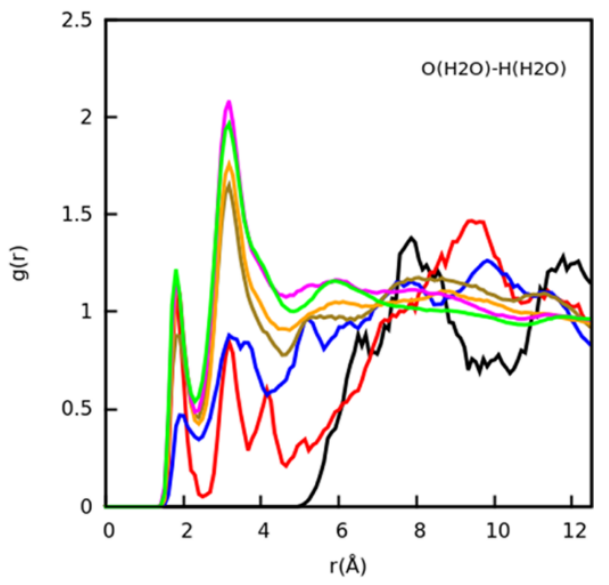

Figure 7. RDFs for interactions $\mathrm{O}\left(\mathrm{H}_{2} \mathrm{O}\right)-\mathrm{O}\left(\mathrm{H}_{2} \mathrm{O}\right)(\mathrm{a})$ and $\mathrm{O}\left(\mathrm{H}_{2} \mathrm{O}\right)-\mathrm{H}\left(\mathrm{H}_{2} \mathrm{O}\right)(\mathrm{b})$.

To finish, we concentrated on how potassium cation distribution evolves with the hydration ratio. The following general tendencies have been observed: (1) the occupation rate of site I (within the hexagonal prism) lowers with the hydration rate, in agreement with the experimental observations for the cobalt-exchanged X-type Faujasite. ${ }^{54}$ (2) The occupation of cationic sites within the sodalite cage also tends to lower with the hydration rate. There are, on average, two potassium cations located in each sodalite cage at the initial hydration rate and rather 1.5 potassium per sodalite cage at high hydrations. With increasing hydration, site II' (within the sodalite cage in front of a 6-MR separating the sodalite cage from a supercage) get also occupied. (3) Furthermore, concerning the cations located within the supercage, site II is fully occupied up to a hydration ratio of $120 \mathrm{H} 20 /$ unit cell. For higher hydration rates, its occupation decreases. This evidence seems coherent with the observed increase of occupation of site II' when hydration increases. In parallel, the occupation of site III' increases with the hydration ratio. (4) Finally, at saturation $\left(240 \mathrm{H}_{2} \mathrm{O} /\right.$ unit cell), a part of the cations located in the supercage tends to displace toward the center of the 12-MR separating the two supercages and partly also toward the center of the supercages. Nevertheless, one needs to keep in mind that we applied fixed unit cell parameters for all the hydration ratios, whereas the unit cell parameters can evolve with hydration. 
(a)

(b)

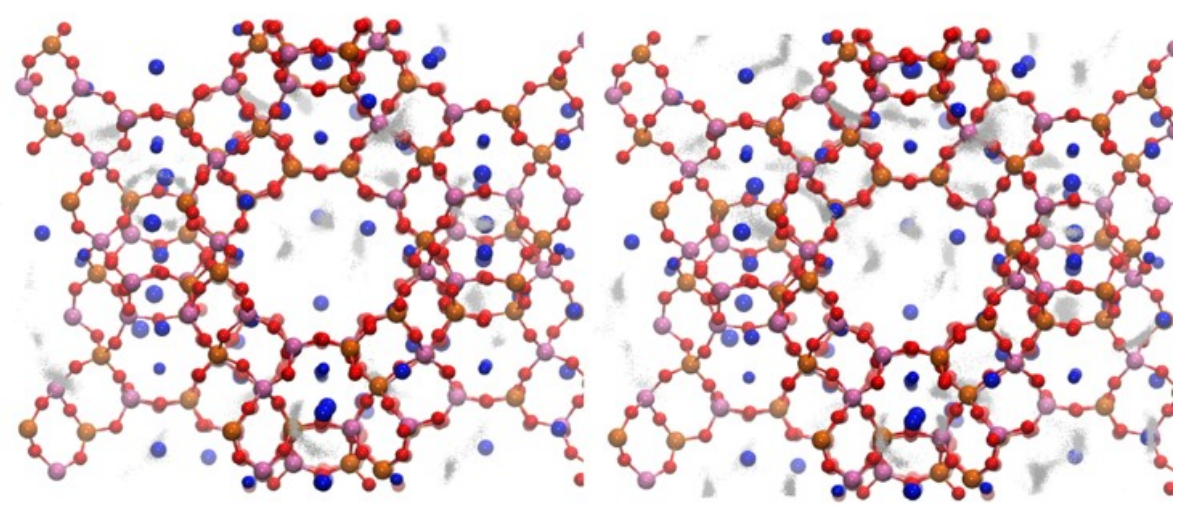

(c)

(d)
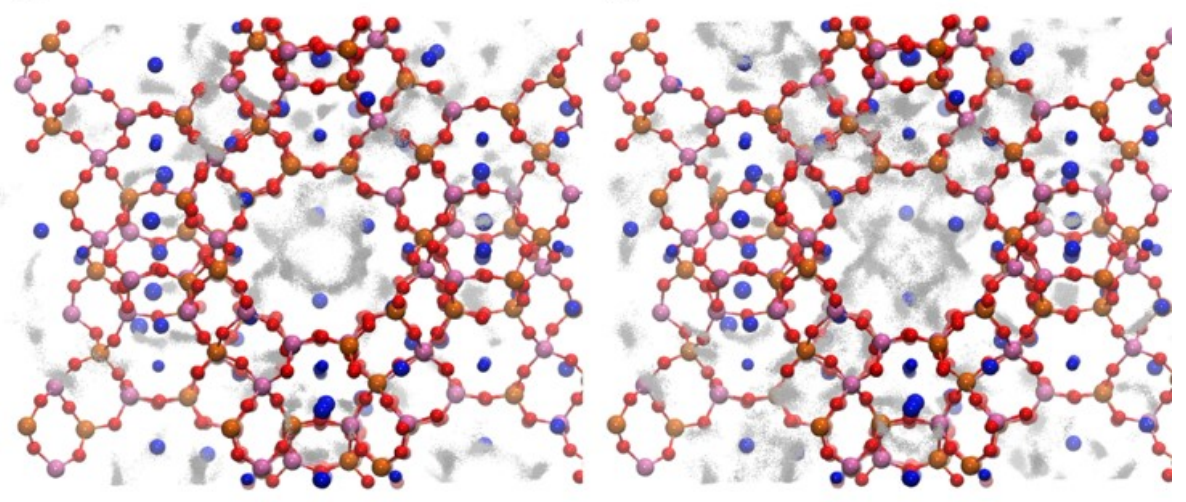

(e)

(f)
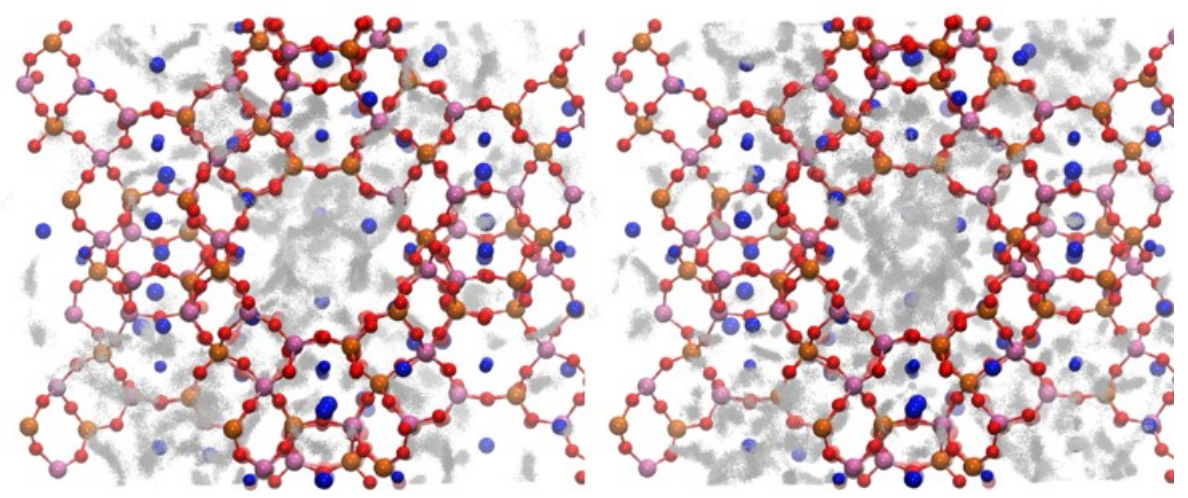

Figure 8. Snapshots of 2000 superimposed configurations of $\mathrm{H}_{2} \mathrm{O}$ adsorbed in one unit cell of the $\mathrm{K}-\mathrm{X}$ zeolite, at respective loadings of (a) 20 $\mathrm{H}_{2} \mathrm{O}$ /unit cell, (b) $40 \mathrm{H}_{2} \mathrm{O}$ /unit cell, (c) $80 \mathrm{H}_{2} \mathrm{O}$ /unit cell, (d) $120 \mathrm{H}_{2} \mathrm{O} /$ unit cell, (e) $160 \mathrm{H}_{2} \mathrm{O} /$ unit cell, and (f) $240 \mathrm{H}_{2} \mathrm{O} /$ unit cell. Red, yellow, pink, blue, and white spheres correspond to atoms of $\mathrm{O}, \mathrm{Si}, \mathrm{Al}, \mathrm{K}$, and $\mathrm{H}$, respectively. Each position of the oxygen atom of the adsorbed water molecules is represented using a gray dot.

\section{Conclusion}

By applying a combination of manometric experiment and several atomic-scale simulation techniques (static lattice optimization, DFT, canonical MC, and GEMC), we have described the adsorption phenomenon of water molecules in the potassium-exchanged X-type faujasite. Our zeolite structural model was first validated through a successful comparison with the accessible literature data of both the unit cell parameter as well as potassium cation distribution. Subsequent DFT calculations of the $\mathrm{K}-\mathrm{X}$ zeolite containing one adsorbed water molecule per unit cell brought to light a highly energetically heterogeneous adsorbent surface. Furthermore, this allowed us to classify the preferential water molecule adsorption sites at zero loading and to describe the underlying adsorbate/adsorbent interactions. The cation in the crystallographic site I' within the sodalite cage has been shown as the most preferential adsorption site, followed by the cation in site III' and finally crystallographic site II, both located in the supercage. These evidence could be successfully contrasted with the available literature data. Moreover, by applying the GEMC simulation, we have validated our force field parameter set through an agreement between the experimental and simulated adsorption isotherms. Thus, we could subsequently describe the microscopic mechanisms of water adsorption as well as the preferential adsorption locations within the $\mathrm{K}-\mathrm{X}$ zeolite at various uptakes, ranging from 
low loading $(\sim 1 \mathrm{wt} \%)$ to saturation $(\sim 29 \mathrm{wt} \%)$. We have evidenced that the sodalite cages are preferentially occupied at low loading, hosting $\sim 63 \%$ of the adsorbed molecules at a hydration ratio of $\sim 1 \mathrm{wt} \%$. On increasing the hydration ratio, the water molecules accommodate rather in the supercages, thus decreasing the proportion of the adsorbate molecules located in the sodalite cages. At saturation, observed for 240 molecules/unit cell, there is an average number of three molecules per sodalite cage and $88 \%$ of the water molecules is located within the supercage. Finally, in a perfect concordance with the DFT results, the water molecules located in the supercage, at any hydration ratio, coordinate preferentially to the potassium cations in crystallographic site III and III' rather than site II. At lower uptakes, water molecules adsorbed within the supercages interact exclusively with cations in sites III and III'. The cations in site II attract water molecules only at uptakes superior to $80 \mathrm{H} 2 \mathrm{O}$ molecules/unit cell, once all cations in site III is occupied by at least one water molecule.

This work gives new insights into the atomic scale of water adsorption in the potassium-exchanged X-type faujasite from both the experimental and molecular simulation point of view. The water location and cation distribution at various hydration rates, from zero loading to saturation, provide crucial information for subsequent $\mathrm{K}-\mathrm{X}$ zeolite applications in various fields such as heterogeneous catalysis, environment remediation, or gas separation.

\section{Acknowledgements}

All the simulation works were accomplished at the HPC Equipex Meso in Strasbourg; the authors would like to acknowledge the Mesocentre for the technical support. ID and TA would like to thank Michael Badawi for fruitful discussions.

\section{References}

(1) Erdős, M.; Geerdink, D. F.; Martin-Calvo, A.; Pidko, E. A.; van den Broeke, L. J. P.; Calero, S.; Vlugt, T. J. H. .; Moultos, O. A. In Silico Screening of Zeolites for High-Pressure Hydrogen Drying. ACS Appl. Mater. Interfaces 2021, 13, 8383-8394.

(2) Khan, F. I.; Ghosal, A. K. Removal of Volatile Organic Compounds from Polluted Air. J. Loss Prev. Process. Ind. 2000, 13, 527-545.

(3) Fischer, M. Simulation-Based Evaluation of Zeolite Adsorbents for the Removal of Emerging Contaminants. Adv. Mater. 2020, 1, 86-98.

(4) Randrianadraina, J.; Deroche, I.; Stephan, R.; Hanf, M.-C.; Sonnet, P. Bis-Chlorinated Aromatics Adsorption in Faujasites Investigated by Molecular Simulation-Influence of $\mathrm{Na}^{+}$Cation. Microporous Mesoporous Mater. 2017, 251, 83-93.

(5) Randrianadraina, J.; Bulot, L.; Deroche, I.; Stephan, R.; Hanf, M.-C.; Chaplais, G.; Daou, J. T.; Simon-Masseron, A.; Patarin, J.; Sonnet, P. Adsorption of Polychlorinated Aromatics in EMT-Type Zeolites: A Combined Experimental-Simulation Approach. J. Phys. Chem. C 2018, 122, 12731-12741.

(6) International Zeolite Association website. https://www.IZA.com (accessed March 15, 2021).

(7) Mercury, M.; Denoyel, R.; Simon-Masseron, A.; Carette, M.; Zerega, Y.; Patarin, J.; Soulard, M.; Reynard, C.; Janulyte, A. Selective Adsorption of 2,3-DCDD and 1,2,3,4-TCDD on *BEA, EMT, FAU and MFI-Type Zeolites as Alternative Adsorbents for On-Line Dioxin Monitoring. Adsorption 2011, 17, 747-758.

(8) Maurin, G.; Llewellyn, P. L.; Bell, R. G. CH4 Adsorption in Faujasite Systems: Microcalorimetry and Grand Canonical Monte Carlo Simulations. Stud. Surf. Sci. Catal. 2007, 160, 335-342.

(9) Frising, T.; Leflaive, P. Extraframework Cation Distributions in X and Y Faujasite Zeolites: A Review. Microporous Mesoporous Mater. 2008, 114, 27-63.

(10) Louisfrema, W.; Paillaud, J.-L.; Porcher, F.; Perrin, E.; Onfroy, T.; Massiani, P.; Boutin, A.; Rotenberg, B. Cation Migration and Structural Deformations upon Dehydration of Nickel-Exchanged NaY Zeolite: A Combined Neutron Diffraction and Monte Carlo Study. J. Phys. Chem. C 2016, 120, 18115-18125.

(11) Porcher, F.; Paillaud, J.-L.; Gaberova, L.; André, G.; Casale, S.; Massiani, P. Monitoring by in Situ Neutron Diffraction of Simultaneous Dehydration and $\mathrm{Ni}^{2+}$ Mobility in Partially Exchanged NaY Zeolites. New J. Chem. 2016, 40, 4228-4235.

(12) Rohling, R. Y.; Uslamin, E.; Zijlstra, B.; Tranca, I. C.; Filot, I. A. W.; Hensen, E. J. M.; Pidko, E. A. An Active Alkali-Exchanged Faujasite Catalyst for $p$-Xylene Production via the One-Pot Diels-Alder Cycloaddition/Dehydration Reaction of 2,5-Dimethylfuran with Ethylene. ACS Catal. 2018, 8, 760-769.

(13) Lu, C.; Liu, T.; Shi, Q.; Li, Q.; Xin, Y.; Zheng, L.; Zhang, Z. Plausibility of Potassium lon-Exchanged ZSM-5 as Soot Combustion Catalysts. Sci. Rep. 2017, 7, 3300.

(14) Kikhtyanin, O.; Ganjkhanlou, Y.; Kubička, D.; Bulánek, R.; Čejka, J. Characterization of Potassium-Modified FAU Zeolites and Their 
Performance in Aldol Condensation of Furfural and Acetone. Appl. Catal., A 2018, 549, 8-18.

(15) Yan, B.; Tao, L.-Z.; Mahmood, A.; Liang, Y.; Xu, B.-Q. Potassium-Ion-Exchanged Zeolites for Sustainable Production of Acrylic Acid by Gas-Phase Dehydration of Lactic Acid. ACS Catal. 2017, 7, 538-550.

(16) Paillaud, J. L.; Caullet, P.; Delmotte, L.; Mougenel, J. C.; Kayiran, S.; Lledos, B. 09-O-01-Localisation of K+ Ions in (Na,K)-LSX and K-LSX Zeolites by Rietveld Analysis and ${ }^{39} \mathrm{~K}$ NMR Spectroscopy. A New Cationic Site in the Orthorhombic Dehydrated K-LSX at Room Temperature. Stud. Surf. Sci. Catal. 2001, 135, 163.

(17) Gibbs, T.; Lewis, D. W. Simultaneous Occupation of SI and SI' Cation Sites in Dehydrated Zeolite LSX. Chem. Commun. 2002, 22, 2660-2661.

(18) Guesmi, H.; Massiani, P.; Nouali, H.; Paillaud, J.-L. A Combined Experimental and Theoretical Study of the Simultaneous Occupation of Sla and SI' Sites in Fully Dehydrated K-LSX. Microporous Mesoporous Mater. 2012, 159, 87-95.

(19) Zhu, L.; Seff, K. Cation Crowding in Zeolites. Reinvestigation of the Crystal Structure of Dehydrated Potassium-Exchanged Zeolite X. J. Phys. Chem. B 2000, 104, 8946-8951.

(20) Lee, Y.; Carr, S. W.; Parise, J. B. Phase Transition upon K+ Ion Exchange into Na-Low Silica X: Combined NMR and Synchrotron X-ray Powder Diffraction Study. Chem. Mater. 1998, 10, 2561-2570.

(21) Kirschhock, C. E. A.; Hunger, B.; Martens, J.; Jacobs, P. A. Localization of Residual Water in Alkali-Metal Cation-Exchanged X and Y Type Zeolites. J. Phys. Chem. B 2000, 104, 439-448.

(22) Hunger, B.; Klepel, O.; Kirschhock, C.; Heuchel, M.; Toufar, H.; Fuess, H. Interaction of Water with Alkali-Metal Cation-Exchanged X Type Zeolites: A Temperature-Programmed Desorption (TPD) and X-ray Diffraction Study. Langmuir 1999, 15, 5937-5941.

(23) Zhu, L.; Seff, K. Reinvestigation of the Crystal Structure of Dehydrated Sodium Zeolite X. J. Phys. Chem. B 1999, 103, 9512-9518.

(24) Jackson, R. A.; Catlow, C. R. A. Computer Simulation Studies of Zeolite Structure. Mol. Simul. 1988, 1, 207-224.

(25) Gale, J. D. GULP: A Computer Program for the Symmetry-Adapted Simulation of Solids. J. Chem. Soc., Faraday Trans. 1997, 93, 629-637.

(26) Mahoney, M. W.; Jorgensen, W. L. A Five-Site Model for Liquid Water and the Reproduction of the Density Anomaly by Rigid, Nonpolarizable Potential Functions. J. Chem. Phys. 2000, 112, 8910-8922.

(27) Dubbeldam, D.; Torres-Knoop, A.; Walton, K. S. On the Inner Workings of Monte Carlo Codes. Mol. Simul. 2013, 39, $1253-1292$.

(28) Cygan, R. T.; Liang, J.-J.; Kalinichev, A. G. Molecular Models of Hydroxide, Oxyhydroxide, and Clay Phases and the Development of a General Force Field. J. Phys. Chem. B 2004, 108, 1255-1266.

(29) Martin, M. G. MCCCS Towhee: A Tool for Monte Carlo Molecular Simulation. Mol. Simul. 2013, 39, 1212-1222.

(30) Snurr, R. Q.; Bell, A. T.; Theodorou, D. N. Prediction of Adsorption of Aromatic Hydrocarbons in Silicalite from Grand Canonical Monte Carlo Simulations with Biased Insertion. J. Phys. Chem. 1993, 97, 13742-13752.

(31) Castillo, J. M.; Silvestre-Albero, J.; Rodriguez-Reinoso, F.; Vlugt, T. J. H.; Calero, S. Water Adsorption in Hydrophilic Zeolites: Experiment and Simulation. Phys. Chem. Chem. Phys. 2013, 15, 17374-17382.

(32) Fuchs, A. H.; Cheetham, A. K. Adsorption of Guest Molecules in Zeolitic Materials: Computational Aspects. J. Phys. Chem. B 2001, $105,7375-7383$.

(33) Fu, C.-L.; Ho, K.-M. First-Principles Calculation of the Equilibrium Ground-State Properties of Transition Metals: Applications to Nb and Mo. Phys. Rev. B 1983, 28, 5480-5486.

(34) Perdew, J. P.; Burke, K.; Ernzerhof, M. Generalized Gradient Approximation Made Simple. Phys. Rev. Lett. 1996, 77, 3865-3868.

(35) Grimme, S. Semiempirical GGA-Type Density Functional Constructed with a Long-Range Dispersion Correction. J. Comput. Chem. 2006, 27, 1787-1799.

(36) Blöchl, P. E. Projector Augmented-Wave Method. Phys. Rev. B: Condens. Matter Mater. Phys. 1994, 50, $17953-17979$.

(37) Kresse, G.; Furthmüller, J. Efficient Iterative Schemes for Ab-Initio Total-Energy Calculations Using a Plane-Wave Basis Set. Phys. Rev. B 1996, 54, 11169-11186. 
(38) Humphrey, W.; Dalke, A.; Schulten, K. VMD: Visual Molecular Dynamics. J. Mol. Graph. 1996, 14, 33-38.

(39) Theoretical and Computational Biophysics Group, Visual Molecular Dynamics software, Beckman Institute for Advanced Science and Technology, University of Illinois, http://www.ks.uiuc.edu/ Research/vmd/ (accessed February 8, 2021).

(40) Hu, M.; Hanson, J. C.; Wang, X. Structure and Thermal Stability of $\left(\mathrm{H}_{2} \mathrm{O}\right)_{4}$ Tetrahedron and $\left(\mathrm{H}_{2} \mathrm{O}\right)_{6}$ Hexagon Adsorbed on NaY Zeolite Studied by Synchrotron-Based Time-Resolved X-ray Diffraction. Ind. Eng. Chem. Res. 2018, 57, 4988-4995.

(41) Boddenberg, B.; Rakhmatkariev, G. U.; Hufnagel, S.; Salimov, Z. A Calorimetric and Statistical Mechanics Study of Water Adsorption in Zeolite NaY. Phys. Chem. Chem. Phys. 2002, 4, 4172-4180.

(42) Perez, C. A. C.; de Resende, N. S.; Salim, V. M. M.; Schmal, M. Water Interaction in Faujasite Probed by in Situ X-ray Powder Diffraction. J. Phys. Chem. C 2017, 121, 2755-2761.

(43) Abrioux, C.; Coasne, B.; Maurin, G.; Henn, F.; Boutin, A.; Di Lella, A.; Nieto-Draghi, C.; Fuchs, A. H. A Molecular Simulation Study of the Distribution of Cation in Zeolites. Adsorption 2008, 14, 743-754.

(44) Breck, D. W. Crystalline Molecular Sieves. J. Chem. Educ. 1964, 41, 678-689.

(45) Bellat, J.-P.; Paulin, C.; Jeffroy, M.; Boutin, A.; Paillaud, J.-L.; Patarin, J.; Di Lella, A.; Fuchs, A. Unusual Hysteresis Loop in the Adsorption-Desorption of Water in NaY Zeolite at Very Low Pressure. J. Phys. Chem. C 2009, 113, 8287-8295.

(46) Plant, D. F.; Maurin, G.; Deroche, I.; Gaberova, L.; Llewellyn, P. L. $\mathrm{CO}_{2}$ Adsorption in Alkali Cation Exchanged Y Faujasites: A Quantum Chemical Study Compared to Experiments. Chem. Phys. Lett. 2006, 426, 387-392.

(47) Purdue, M. J.; Qiao, Z. Molecular Simulation Study of Wet Flue Gas Adsorption on Zeolite 13X. Microporous Mesoporous Mater. 2018, 261, 181-197.

(48) Nour, Z.; Berthomieu, D.; Yang, Q.; Maurin, G. A Computational Exploration of the CO Adsorption in Cation-Exchanged Faujasites. J. Phys. Chem. C 2012, 116, 24512-24521.

(49) Thommes, M.; Kaneko, K.; Neimark, A. V.; Olivier, J. P.; Rodriguez-Reinoso, F.; Rouquerol, J.; Sing, K. S. W. Physisorption of Gases, with Special Reference to the Evaluation of Surface Area and Pore Size Distribution (IUPAC Technical Report). Pure Appl. Chem. 2015, 87, 1051-1069.

(50) Dzhigit, O. M.; Kiselev, A. V.; Mikos, K. N.; Muttik, G. G.; Rahmanova, T. A. Heats of Adsorption of Water Vapour on XZeolites Containing $\mathrm{Li}^{+}, \mathrm{Na}^{+}, \mathrm{K}^{+}, \mathrm{Rb}^{+}$, and $\mathrm{Cs}^{+}$Cations. Trans. Faraday Soc. 1971, 67, 458-467.

(51) Moïse, J. C.; Bellat, J. P.; Méthivier, A. Adsorption of Water Vapor on X and Y Zeolites Exchanged with Barium. Microporous Mesoporous Mater. 2001, 43, 91-101.

(52) Calero, S.; Gómez-Álvarez, P. Hydrogen Bonding of Water Confined in Zeolites and Their Zeolitic Imidazolate Framework Counterparts. RSC Adv. 2014, 4, 29571-29580.

(53) Shirono, K.; Endo, A.; Daiguji, H. Molecular Dynamics Study of Hydrated Faujasite-Type Zeolites. J. Phys. Chem. C 2005, 109, 3446-3453.

(54) Jeffroy, M.; Borissenko, E.; Boutin, A.; Di Lella, A.; Porcher, F.; Souhassou, M.; Lecomte, C.; Fuchs, A. H. Evidence of a Framework Induced Cation Redistribution upon Water Adsorption in Cobalt Exchanged X Faujasite Zeolite: A Joint Experimental and Simulation Study. Microporous Mesoporous Mater. 2011, 138, 45-50. 